\title{
DOUBLE ANTERIOR TEMPORALIS FASCIA MYRINGOPLASTY IN LARGE CENTRAL TYMPANIC PERFORATION
}

\section{Ezzeddin M. Elsheikh; Magdy M. Abdel fatah and And Ibrahim E. Ibrahim \\ Otorhinolaryngology Department, Faculty of Medicine, Zagazig University}

ABSTRACT

Objective: This study aimed to study double anterior temporalis fascia myringoplasty in primary safe large central tympanic perforation regarding graft uptake and hearing gain.

Methods: The present work included the study of fourteen (14) patients who presented with symptoms suggestive of chronic suppurative otitis media (CSOM) to E.N.T. outpatient clinic, Zagazig university hospitals. All patients were suffering from mucosal type of CSOM and the tympanic membrane perforations are of large size; subtotal perforation. Temporalis Fascia Tympanoplasty type I operation was performed for all patients with double anterior layer technique.

Results: This study included Fourteen (14) patients suffering from mucosal type of CSOM. They included 5 males $(35 \%)$ and 9 female $(65 \%)$. The age of patients at the time of presentation was maximum of 37 years and minimum of 12 years with a mean of 23.71 years. The main presenting symptom was hearing impairment in all the fourteen $(100 \%)$ patients. Ear discharge was the second common presenting symptom. The rate of success in our fourteen cases was $100 \%$ in our study, the audiometric tests performed at the 3rd postoperative month revealed that the mean airbone gap decreased by $20 \pm 1 \mathrm{~dB}$.

Key words; Underlay tympanoplasty, Over-underlay tympanoplasty, Large perforation

Corresponding authors: Tel.; 01279725524

E.mail:ibrahimelsayed604@gmail.com

\section{INTRODUCTION}

O ne of the common sequelae of chronic otitis media is tympanic membrane (TM) perforation, which can cause hearing loss and otorrhea. It is essential for every otolaryngologist to know how to repair tympanic membrane perforation. The two classic methods for reconstruction of TM perforation have been medial (underlay) or lateral (overlay) graft technique. In the underlay technique, the graft is placed entirely medial to the remaining TM and malleus while in overlay technique, the graft is placed lateral to the annulus, and any remaining fibrous middle layer after the squamous layer has been carefully removed, each of these techniques has its advantages and disadvantages ${ }^{[1]}$.

The long term aim of tympanoplasty is to reconstruct the tympanic membrane and the sound conducting mechanism. Since the introduction of tympanoplasty by Wulstein and Zollner ${ }^{[2]}$, numerous graft materials have been used for the closure of the defective membrane: skin, fascia lata, temporalis fascia, vien, perichondrium and dura mater. To date, temporalis fascia remains the most commonly employed material for tympanic membrane reconstruction with success rate of $93-97 \%$ in primary tympanoplastices ${ }^{[3]}$.

Successful closure of tympanic membrane following myringoplasty, is related to perforation size, site of perforation, duration of discharging ear, the associated pathology in the middle ear, training of surgeon, surgical technique, graft material, previous myringoplasty and smoking history [4].

The anterior TM perforation is difficult to repair because of less vascularity than posterior tympanic membrane and the anterior bony overhang that lacks visualization. Because of reduced vascularity in the anterior tympanic membrane, there is a greater risk of necrosis and reabsorption of the fascia graft ${ }^{[5]}$.

When the medial graft technique is used to repair anterior or subtotal TM perforation, the anterior portion of the fascia graft may fall away, resulting in reperforation and obliteration of anterior part of middle ear cavity. Although the lateral graft technique has a higher success rate for the reconstruction of anterior or subtotal TM 
perforation, serious lateralization of graft may occur. These problems have been managed by a variety of surgical techniques, such as the use of sandwich graft tympanoplasty, over-under tympanoplasy, and up till now a still better method is needed to repair anterior perforation ${ }^{[6]}$.

Temporalis fascia is the commonly used graft material because it is an autograft with excellent chance of take, it is close to the site of operation making its harvest easier,it has a low basal metabolic rate brightening its success rate and its thickness is more or less similar to that of tympanic membrane ${ }^{[7]}$.

Aim of the study: This study aimed to study double anterior temporalis fascia myringoplasty in primary safe large central tympanic perforation regarding graft uptake and hearing gain.

\section{MATERIALS AND METHODS}

The present work included the study of fourteen (14) patients who presented with symptoms suggestive of chronic suppurative otitis media to E.N.T. outpatient clinic, Zagazig university hospitals. All patients were suffering from mucosal type of chronic suppurative otitis media and the tympanic membrane perforations are of large size; subtotal perforation.

Majority $(60 \%)$ of the patients was of rural habitant and rest (40\%) was from urban areas. All patients had complaints of discharging ear of varied duration and varied degree of hearing loss.
Temporalis Fascia Tympanoplasty type I operation was performed for all patients (100\%).

\section{All cases were subjected to:}

- Thorough history taking.

- ENT examination with special care to the diseased ears.

- Tunning fork tests (Rinne' and Weber's tests).

- Routine laboratory investigations; CBC, PT, PTT, INR, liver functions, viral markers (HBV,HCV), kidney functions, blood sugar and urine analysis.

- Preoperative audiological assessment including pure tone audiogram, speech discrimination.

Exclusion criteria:

- Patients below 12 years.

- Active discharge from the middle ear.

- Nasal allergy, which should be controlled before surgery.

- When the other ear is dead.

- Otitis externa.

- Bad general conditions as (bad chest condition, diabetic patients, Liver cell failure, kidney failure and heart failure patients).

- Patients with chronic persistent otorrhea, granulation tissue and cholesteatoma.

- Patients who failed to attend to scheduled postoperative follow-up.

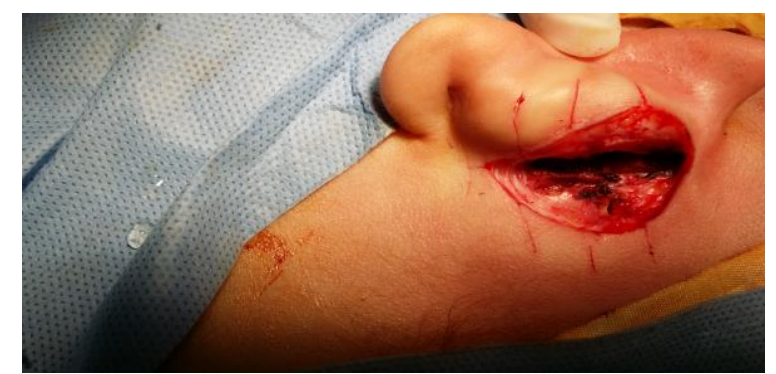

Figure (1): Postauricular incision

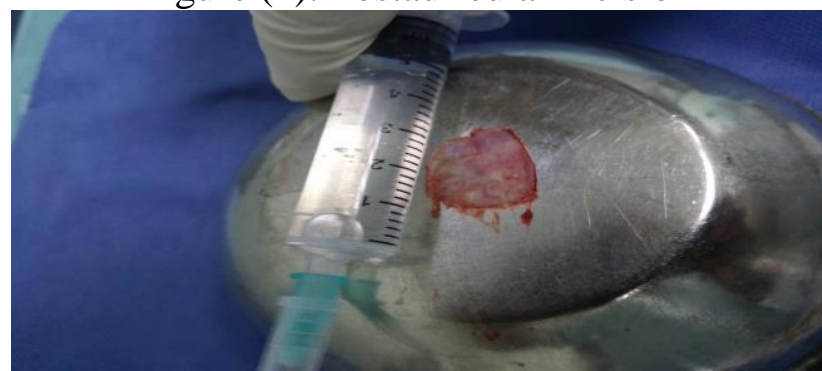

Figure (2): Temporalis fascia graft taken. 


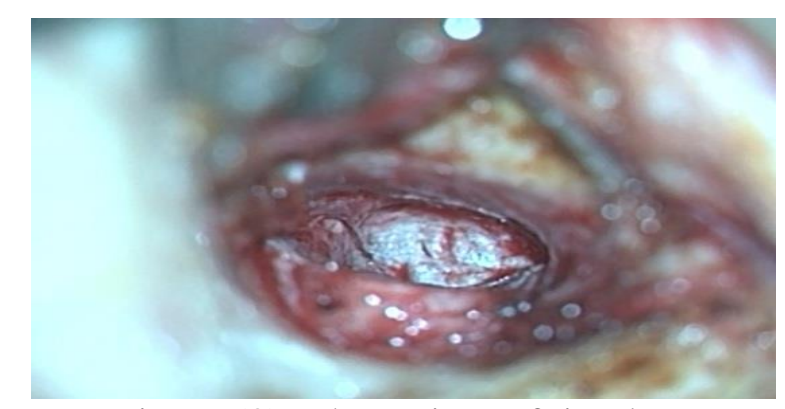

Figure (3): The main graft in place

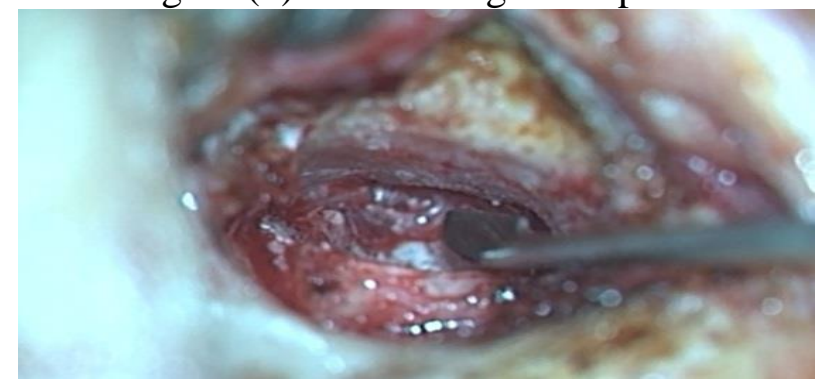

Figure (4): The second small anterosuperior graft in place

\section{RESULTS}

This study included Fourteen (14) patients suffering from mucosal type of chronic suppurative otitis media. They included 5 males $(35 \%)$ and 9 female $(65 \%)$. The age of patients at the time of presentation was maximum of 37 years and minimum of 12 years with a mean of 23.71 years.

The main presenting symptom was hearing impairment in all the fourteen $(100 \%)$ patients. Ear discharge was the second common presenting symptom. On examination the discharge was odourless, mucopurulent not bloody, intermittent and stopped with medication. Tinnitus was accompanying symptom in 7 patients $(50 \%)$.

Microscopic examination of the affected ears showed subtotal perforation for all patients $(100 \%)$.

Side of perforation distribution:

Table (1): Side of perforation distribution

\begin{tabular}{llrrr}
\hline & & & $\%$ & \\
\hline Side & Left ear & $\mathbf{8}$ & $\mathbf{5 7 . 1}$ \\
\cline { 2 - 5 } & Right ear & $\mathbf{6}$ & $\mathbf{4 2 . 9}$ \\
\cline { 2 - 5 } & Total & $\mathbf{1 4}$ & $\mathbf{1 0 0 . 0}$ \\
\hline
\end{tabular}

The distribution of the operated ear in this study was 6 right ear (42.9\%) and 8 left ear (57.1\%).

Perforation size and graft uptake distribution:

Table (2): Perforation size and graft uptake distribution

\begin{tabular}{lllll}
\hline & & $\mathrm{N}$ & $\%$ \\
\hline Perforation size & Large Subtotal & $\mathbf{1 4}$ & $\mathbf{1 0 0 . 0}$ \\
\hline Graft uptake & Taken & $\mathbf{1 4}$ & $\mathbf{1 0 0 . 0}$ \\
\hline
\end{tabular}

Air bone gap pre and post distribution:

Table (3): Air bone gap pre and post distribution

\begin{tabular}{lrr}
\hline & ABG pre & ABG post \\
\hline $\mathbf{N}$ & 14 & 14 \\
\hline Mean \pm SD & $28.92 \pm 8.3$ & $9.28 \pm 4.7$ \\
\hline Median & 30.00 & 10.00 \\
\hline Range & $15-45$ & $5-15$ \\
\hline
\end{tabular}

Hearing improvement: 
Evaluation of hearing was done by preoperative and post-operative measuring of the average air and bone conduction thresholds recorded at the following frequencies: 250 $\mathrm{Hz}, 500 \mathrm{~Hz}, 1000 \mathrm{~Hz}$ and $2000 \mathrm{~Hz}$.

The improvement in hearing was measured by subtracting the average air bone gap ABG preoperative and postoperative.
There was closure of the air bone gap within $15 \mathrm{~dB}$ in 14 patients $(100 \%)$ this means that hearing improved in about $100 \%$ of patients.

The following table summarizes hearing results:-

Table (4): Summary of hearing results and their percentage

\begin{tabular}{lll}
\hline Air-Bone gap10 dB or less & A-B gap 11-15 dB & A-B gap >15dB \\
\hline 11 patients $(78.5 \%)$ & 3 patients $(21.5 \%)$ & 0 patients $(0 \%)$ \\
\hline
\end{tabular}

Post-operative pain:

Post operative pain was reported in 3 patients $(22.5 \%)$ in the first post operative day and persisted only for 2-3days and was described as discomfort up to $4 / 10$ on the pain scale in 2 patients.

The following table summarizes postoperative pain distribution:-

Table (5): Postoperative pain distribution among patients

\begin{tabular}{|l|l|l|l|l|}
\hline No pain & Mild 1-3/10 & Moderate4-6/10 & Severe 7-9/10 & Worst pain 10/10 \\
\hline 11 patients & 2 patients & 1 patients & 0 & 0 \\
\hline
\end{tabular}

DISCUSSION

The long history of tympanic membrane repair goes back to 1640 when Banzer used pig bladder in grafting and to 1878 when Berthold repaired a perforation using a fullthickness skin graft, coining the term "myringoplasty",[8].

In the 1950s, Zollner and Wullstein developed new myringoplasty techniques following the introduction of antibiotics and microsurgery. Since then, various techniques have been developed to improve tympanoplasty results ${ }^{[9]}$.

It is often reported that repair of anterior or large subtotal perforation is less successful than that of central perforations because it is technically more difficult ${ }^{[\mathbf{1 0}]}$.

Primrose et al (1986) ${ }^{[11]}$ reported that the anterior tympanomeatal angle remains the main problem area in anterior marginal perforations with both conventional onlay and underlay techniques. He described a variation of Gerlach's quilting technique to overcome the problem and this modification has proven to be both simple and effective. When the graft is prepared a small tag is fashioned anteriorly and later pulled through a small tunnel under the anterior-superior annulus. This prevents the graft falling away anteriorly without producing the blunting associated with more extensive undermining of the anterior annulus.

In our study we don't have to make a tunnel which is considered difficult to some extent, we only use double fascial graft anterosuperior and anterioinferior without producing the blunting associated with more extensive undermining of the anterior annulus also.

In a study conducted by Sharp, Terzis and Robinson (1992) ${ }^{[10]}$ they reported that surgical closure of the anteriorly located tympanic membrane perforation can present a problem. The lack of anterior support for the graft frequently leads to graft failure if an underlay method is used whereas anterior blunting is a complication of onlay techniques in this situation. The experience with the Kerr flap, an underlay graft fashioned to include a tab of fascia which is placed laterally under the annulus and the anterior meatal skin was presented.

In our study we overcome this problem by using temporalis fascia in underlay fashion with anterosuperior and anterioinferior douple graft as a support for the main graft without producing blunting with the others advantages of underlay technique as it is a simple technique no risk 
of lateralization with high success rate that considered being the disadvantages of overlay procedure.

The underlay and the overlay procedures are presently the two most widely used techniques. The former, a relatively simple technique, places the graft under the remaining drum and malleus. In the latter technique, which is considered relatively difficult, the graft is placed lateral to the annulus after the squamous layer has been carefully removed. Each of these techniques has its advantages and disadvantages ${ }^{[12]}$.

Today, the underlay procedure is preferred over the overlay procedure because there is the risk of blunting coupled with the greater time and complexity needed for the latter technique ${ }^{[13]}$.

Primrose et al, (1986) ${ }^{[11]}$ were able to improve graft tension by using an anterior tunnel created under the annulus. Gristwood et al, (1993) [14] described an underlay myringoplasty creating two anterior tunnels for graft stabilization. Sauvage et al, (1998) [15] presented a surgical technique that included the creation of a large anterior flap for stabilizing the fascia. In our study we improve graft stabilization by using double anterior fascial graft without creation of anterior tunnel or large anterior flap. In a series of 273 ears, Glasscock (1973) [16] reported that the success rate was $91 \%$ with the overlay technique and $96 \%$ with the underlay technique, Sheehy and Anderson (1980) ${ }^{[17]}$ reported that the rate of success in 472 overlay tympanoplasty surgeries was 97\%.In a series of 554 overlay grafts, Rizer (1997) ${ }^{[18]}$ reported a success rate of $95.6 \%$. The same author's success rate in 158 underlay grafts was $88.8 \%$.

In our study the rate of success in fourteen cases of underlay tympanoplasty surgeries was $100 \%$ that may be because of our technique or our senior surgeon and may be also the precise number. The graft uptake for myringoplasty done by the senior faculty was $86.2 \%$, by the junior faculty was $85.2 \%$, and by residents was only $77.2 \%$. The result was however not statistically significant ${ }^{[19]}$. Onal et al, (2005) [20] Vartiainen and Nuutinen (1993) ${ }^{\text {[21] }}$ and Black \& Wormald (1998) ${ }^{[22]}$ have reported inferior success rates for junior surgeons as compared with senior surgeons. Emir et al, in his 607 patients with at least 12 months of follow-up found that the graft uptake for residents was $86.2 \%$, whereas, for the senior faculty it was $94.8 \%{ }^{[23]}$.

Ralli and Giovanni (2000) ${ }^{[24]}$ used underlay anchored myringoplasty which utilizes anterior and posterior tunnels to achieve proper tension of the tympanic membrane as well as lateral traction of the malleus handle. It resulted in drum healing $(91.7 \%)$ and pure tone average (PTA) post operatively was $27 \mathrm{~dB}$ as compared with 55 $\mathrm{dB}$ preoperatively.

In our study we resulted in drum healing $(100 \%)$ and pure tone average (PTA) post operatively was $9.2 \mathrm{~dB}$ as compared with $28.9 \mathrm{~dB}$ preoperatively.

The under-over tympanoplasty is a combination of the underlay and overlay techniques and has been developed with the aim of minimizing the disadvantages inherent in the other two techniques. This may explain why the under-over procedure is becoming widespread as a means of tympanic membrane repair ${ }^{[13]}$.

Stage et al, (1992) ${ }^{[25]}$ who supported the under-over procedure when used for perforations anterior to the handle of the malleus, reported a success rate of $91 \%$ in 39 ears. A similar success rate $(90 \%)$ was attained by Kartush et al, (2002) ${ }^{[13]}$ in a series of 120 patients who underwent underover tympanoplasty. In a study conducted by Jung et al, (2005) in a series of 200 patients they reported that there were four failures in 100 operated cases (96\% success rate) with underlay graft method for anterior TM perforation due to infection and reperforation. In the under-over tympanoplasty, there were three failures of 100 operated cases (97\% success rate) due to a postoperative infection, anterior blunting and recurrent cholesteatoma. In our study we also overcome under-over tympanoplasty technique as our success rate was $100 \%$ as there were no postoperative infection, anterior blunting and recurrent cholesteatoma.

A fascial graft may become detached from the umbo because of postoperative 
shrinking and scarring in the healing process theoretically, and this conduction will cause a decrease in the hearing levels ${ }^{[26]}$. In our study we didn't face this problem and fascial graft not detached from the umbo because of the double graft layers and its good middle ear support with the gel foam. An air-bone gap closure to within $10 \mathrm{db}$ or less was considered successful, as adopted by many authors, Dornhoffer (1997) ${ }^{[27]}$; Raafat et al., (1999) [28]; Gerber et al., (2000) ${ }^{\text {[29] }}$ and Maury et al., $(2001)^{[30]}$.

In our study, the audiometric tests performed at the $3 \mathrm{rd}$ postoperative month revealed that the mean air-bone gap decreased by $20 \pm 1 \mathrm{~dB}$. The current study comprised 14 patients suffering from tubotympanic type of chronic suppurative otitis media with large anterior tympanic membrane perforation. The study included 5 males and 9 females with the mean age of 23.7 years.

The distribution of cases according to their sex and age revealed no significant statistical difference. Dornhoffer (1997) ${ }^{\text {[27] }}$ studied 42 patients with tubotympanic chronic suppurative otitis media. They were 20 males and 22 females with the mean age of $23.6 \pm 5.9$ years. He stated that analysis of the patient's data revealed that sex and age at the time of surgery had no impact on postoperative hearing results.

Majority $(60 \%)$ of the patients was of rural habitant and rest (40\%) was from urban areas. All of the patients had complaints of discharging ear of varied duration and varied degree of hearing loss. Dry ear for at least 3 months was the main inclusion criteria in our patients preoperative. In all the cases both preoperative and postoperative audiometry were performed and the results were compared. Postoperative pure tone audiometry was performed only in successful closure cases after 12 weeks follow-up period. All patients operated by underlay technique.

In our study, the success rate of tympanoplasty performed using the underlay technique was $100 \%$ in 14 patients however the number of patients was less than other comparative studies. In this study, there were no such complications as graft lateralization, canal stenosis or blunting, no retractions, No epithelial pearls, no wound infection, hematomas, perichondritis, auricular deformities, no scar deformity as keloid or gaped suture. Also no sensorineural hearing loss was identified.

\section{CONCLUSION}

It can be concluded from this study that the temporalis fascia is suitable and efficient graft material in tympanoplasty. The double layer temporalis fascia graft is the most suitable one in both postoperative graft taking and hearing improvement for large anterior tympanic membrane perforation. Study with large number of patients for further evaluation is recommended.

\section{REFERENCES}

1. Kartush J.M., Michaelides E.M., Becvarovski A. \& LaRouere M.J., "Over-under tympanoplasty", Laryngoscope, 2002, 112: 802-807

2. Wulstein: Quoted from Myringoplasty. Ann Otol Rhinol Laryngol published by Cavaliere M; 1956; 89: 331-4.

3. Cavaliere M., Mottola G., Rondenilli M., et al.: Myringoplasty. Ann Otol Rhinol Laryngol; 2009; 89: 331-4.

4. Ashfaq M., Aasim MU. And Khan N.: Mringoplasty: Anatomical and functional results. Pak Armed Force Med J; 2004; 54(2):155-8.

5. Richard: Quoted from Myringoplasty. Ann OtolRhinolLaryngol by Cavaliere $\mathrm{M}$ et al. 2006; 89:331-4.

6. Timothy: Middle Ear, Chronic Suppurative Otitis, Surgical Treatment. J Laryngol Otol; 2009; 27: 308-17.

7. Storrs: Quoted from Cartilage tympanoplasty methods: Proposal of a classification. Otolaryngology-Head and Neck Surgery (2008) by Tos M; 1961; 139: 747-58.

8. House WF: Myringoplasty. Arch Otolaryngol; 1960 71:399-404.

9. Schwaber MK. (1986): Postauricular undersurface tympanic membrane grafting: some modifications of the "swinging door" technique. Otolaryngol Head Neck Surg 95:182-187.

10.Sharp JF, Terzis TF and Robinson J. : "Myringoplasty for the anterior perforation: experience with the kerr flap", J. Laryngol Otol, 1992, 106:14-6.

11.Primrose WJ, Kerr AG.: "The anterior perforation", Clin Otolaryngol, 1986; 11:175176. 
12.Singh M., Rai A., Bandyopadhyay S. \& Gupta S.C.: "Comparative study of the underlay and overlay techniques of myringoplasty in large and subtotal perforations of the tympanic membrane", $\mathrm{J}$. Laryngol. Otol., 2003, 117: 444-448.

13.Kartush J.M., Michaelides E.M., Becvarovski A. \& LaRouere M.J., "Over-under tympanoplasty", Laryngoscope, 2002, 112: 802-807

14.Gristwood R E and Venables W N: Growth rate and recurrence of residual epidermoid cholesteatoma after tympanoplasty ,Clinical Otolaryngology \& Allied Sciences, Volume 1, Issue 2, pages 169-182, April 1993.

15.Sauvage JP, Heutebise F, Pugraud S: Hammock Myringoplasty (technique, results) J. Otolaryngol;1998, 4: 319-331.

16.Glasscock ME III: Tympanic membrane grafting with fascia: overlay vs. undersurface technique. Laryngoscope; 1973, 83:754-770.

17.Sheehy J.L. \& Anderson R.G. : "Myringoplasty: a review of 472 cases", Ann. Otol. Rhinol. Laryngol, 1980, 89: 331-334.

18.Rizer FM : Overlay versus underlay tympanoplasty. Part 1: historical review of the literature; part II: the study. Laryngoscope; 1997, 107: 26-36.

19.Browning GG, Merchant SN, Kelly G, Swan IR, Canter R, McKerro WS. : Chronic otitis media. In: Gleeson M, editor. Scott-Brown's Otorhinolaryngology, Head and Neck Surgery. 7th ed.Vol 3.London: Edward Arnold; 2008:3345-95.

20.Onal K, Uguz MZ, Kazikdas KC, Gursoy ST, Gokce H.: A multivariate analysis of otological, surgical and patient-related factors in determining success in myringoplasty. Clin Otolaryngol 2005; 30(2):115-120.

21.Vartiainen E, and Nuutinen J. : Success and pitfalls in myringoplasty: follow-up study of 404 cases. Am J Otol 1993;14:301-5.

22.Black JH. And Wormald PJ.: Myringoplasty effects on hearing and contributing factors. S Afr Med J 1995; 85(1):41-43.

23.Emir H, Ceylan K, Kizilkaya Z, Gocmen H, Uzunkulaoglu H, Samim E.: Success is a matter of experience: type 1 tympanoplasty: influencing factors on type 1 tympanoplasty. Eur Arch Otorhinolaryngol 2007; 264(6):595-599.

24.Ralli , Giovanni M.D: Graft stabilization in tympanic membrane Reconstruction; 2000 , Volume 94, Issue 6, pages 843-845.

25.Stage J. \& Bak-Pederson K.: "Underlay tympanoplasty with the graft lateral to the malleus handle", Clin Otolaryngol Allied Sci.
1992; 17(1):6-9.

26.Wullstien H.: Tympanoplasty. The problem of the free graft and the mucous membrane graft. Arch Otolaryngol 1960; 71: 363-368.

27.Dornhoffer JL: Hearing results with cartilage tympanoplasty. Laryngoscope; 1997, 107: 1094-99.

28.Raafat, S., Fayek, A., El-Sharkawy, L., Zakaria, M. : Tympanoplasty using perichondrial-cartilage composite graft.Med. J. Cairo Univ.; 1999, 67(3): 833 - 837.

29. Gerber MJ, Mason JC and Lambert PR: Hearing results after primary cartilage tympanoplasty. Laryngoscope; 2000, 110: 1994-9.

30. Maury M, Neto $G$ and Fuchs SC: Evaluation of inlay butterfly cartilage tympanoplasty A randmaized clinical trial. Laryngoscope; 2001, 111: 1479-1485. 